\title{
Effectiveness of the use of bedrails in preventing falls among hospitalized older adults: a systematic review protocol
}

\author{
Paulo Marques ${ }^{1,4}$ \\ Carmen Queirós $s^{2,4}$ \\ João Apóstolo ${ }^{3,4}$ \\ Daniela Cardoso $0^{3,4}$
}

1. Center for Health Technology and Services Research (CINTESIS), Escola Superior de Enfermagem do Porto (Nursing School of Porto), Porto, Portugal

2. Centro Hospitalar do Porto, Escola Superior de Enfermagem do Porto (Nursing School of Porto), ICBAS - UP, Porto, Portugal

3. Health Sciences Research Unit: Nursing, Nursing School of Coimbra, Coimbra, Portugal

4. Portugal Centre for Evidence Based Practice: an Affiliate Center of the Joanna Briggs Institute

\section{Corresponding author: \\ Paulo Marques \\ paulomarques@esenf.pt}

\section{Review question/objective}

The objective of this review is to identify the effectiveness of the use of bedrails in preventing falls among hospitalized older adults when compared with no use of bedrails or any type of physical restraints.

More specifically, the review will focus on the following questions:

- What is the effectiveness of the use of bedrails in preventing falls among hospitalized older adults when compared with no use of bedrails?

- What is the effectiveness of the use of bedrails in preventing falls among hospitalized older adults when compared with no use of physical restraints?

\section{Background}

Falls are a major problem today affecting people of any age, but they have an increased importance in the elderly. They are the leading cause of injury or death among older adults. ${ }^{1}$ A fall can be defined as an event whereby an individual comes to rest on the ground or another lower level with or without loss of consciousness. $^{2}$

Direct consequences of a fall can vary from bruises and minor injuries (28\%) to severe wounds of the soft tissues $(11,4 \%)$ and bone fractures $(5 \%){ }^{3}$ Moreover, falls can induce a fear of future falls, leading 
to a decrease in function and an increased dependency on care, ${ }^{4}$ increased length of stay in hospital ${ }^{5}$ and higher risk of institutionalization. Falls have a significant impact not only on the quality of life of the older person, but also on their families and society as a whole, resulting in an increase in healthcare costs. $^{6}$

The causes of falls are complex and multifactorial. They are associated with an individual patient's health issues, treatment, disabilities, mental state, behavior and environment. ${ }^{7}$ Hospitalized older people are particularly vulnerable to falls. In hospital, approximately $2 \%$ to $12 \%$ of patients experience at least one fall during their hospital stay. ${ }^{8-9}$ The incidence of falls in hospitals shows great variability (2.2-17.1\% falls per 1000 patients days), depending on ward type and hospital population. ${ }^{10-11} \mathrm{~A}$ significant proportion of falls (up 22\%) in acute hospitals occur from beds. ${ }^{12}$ There were around 44,000 reports to the National Reporting and Learning System (UK), between 1 September 2005 and 31 August 2006, of patients who appeared to have fallen from the bed in acute and community hospitals, mental health and learning disability units. ${ }^{7}$ Of this number around 90 patients fractured their neck of femur, and 11 patients died as a result of their falls.

The prevention of falls is commonly considered an indicator of quality of care. Therefore, health institutions and professionals treat the identification and implementation of strategies to prevent or minimize their effects as a high priority.

Fall prevention interventions involving physical restraints are still common and considered a primary preventative measure, despite controversy in their use, and the increase in technological alternatives. ${ }^{13}$ Restraint is defined as "a mechanism used to control or modify a person's behavior". ${ }^{1(\mathrm{p} .100)}$ On the one hand, the restriction of movement firstly can lead to aggression, with more serious consequences than the fall itself. Second, restricting people's actions may infringe upon their basic rights and dignity. Protection and promotion of a respect for autonomy, integrity and dignity among older adults must be considered in the decision-making process regarding when to use restraints, ${ }^{15}$ and nurses from clinical practice should consider a solid rationale before authorizing their use.

One of the most frequently used restraint interventions are bedrails, ${ }^{14,16}$ (also called side rails, cotsides or safety rail ${ }^{7}$ ) and as a restraint is defined as the use of two full rails or four half-rails. Prevalence in use of bedrails in hospitals ranges from 8 to $64 \% .^{7,17-19}$ However, bedrails can be also classified as non-restrictive. ${ }^{20}$ The argument for the effectiveness of bedrails is contradictory. In some cases bedrails are justified both ethically and legally, and therefore not considered a restraint restriction, ${ }^{21}$ for example, in situations where the bedrails are implemented at the request of the person, in order to feel safe or to support their movement. ${ }^{21}$ However, if the bedrails purposefully stop a patient from leaving their bed, this may be classed as a form of restraint. ${ }^{22}$

In spite of the extensive use of bedrails to prevent falls in care, there have been serious incidents reported to the MHRA (Medicines and Healthcare Products Regulatory Agency) ${ }^{16}$ directly related to the use of bedrails where reports have suggested that the use of bedrails could result in serious injuries and even death. ${ }^{25-26}$ Of the reports of falls from beds made to the National Reporting and Learning System, $61 \%$ did not include information on whether bedrails were in use or not, $8 \%$ stated that the falls occurred when bedrails were being used, and $31 \%$ stated that bedrails were not in use when the falls occurred. ${ }^{7}$

The question of the effectiveness of bedrails to prevent falls cuts across all societies and cultures with a significant meaning to the clinical practice of nurses. These are professionals who implement the 
intervention with this goal, often with mixed feelings. ${ }^{28}$ Nursing staff and patients' families are often confronted with feelings of guilt and anxiety. ${ }^{28}$

Reviews previously conducted on the subject of restraint did not focus specifically on bedrails or their use on the older population. They pointed out limitations such as the poor quality of studies and found little evidence to answer the question of the effectiveness of bedrails in preventing falls/injury. For example, a Joanna Briggs Institute (JBI) review of the effectiveness of physical restraint in reducing falls did not address bedrails as a specific intervention. ${ }^{13}$ Another example is a Cochrane review titled "Interventions designed to prevent healthcare bed-related injuries in patients". ${ }^{29}$ The evidence base at last review could not conclude with any definitive evidence on the effectiveness due to limitations and poor predictive power. Even though research on restraint use in general has been given considerable attention since the mid-1980s, ${ }^{30}$ research which specifically addresses the use of bedrails has been limited. ${ }^{31}$ This review will attempt to review the literature base beginning from 1980 and see if the evidence has become more definitive.

\section{Keywords}

Bedrails; Hospital; Hospitalized; Aged; Elderly; Falls; Side rails; Cot sides; Safety rail

\section{Inclusion criteria}

\section{Types of participants}

The quantitative component of this review will consider studies that include hospitalized adults (female and male), 65 years and over with any clinical condition in a non-intensive care unit (ICU).

\section{Types of intervention(s)/phenomena of interest}

The quantitative component of the review will consider studies that evaluate the use of bedrails as a restraint to prevent falls among older adults in non-ICUs compared to no use of bedrails or any type of physical restraints, for example: bedrails versus no bedrails, and bedrails versus no wrist or ankle ties.

\section{Types of outcomes}

This review will consider studies that include the following outcome measures:

Primary outcomes - Number of patients who fall or the number of falls per patient.

Secondary outcomes - Number of head trauma, bone fractures or soft tissue injuries.

\section{Types of studies}

The quantitative component of the review will consider any randomized controlled trials (RCTs) that examine the effectiveness of the use of bedrails in preventing falls among hospitalized older adults when compared with no use of bedrails or any type of physical restraints.

In the absence of RCTs, other research designs of a quantitative nature, such as non-randomized controlled trials, before and after studies, cohort studies, case control studies, descriptive studies, case series/reports and expert-opinion, will be considered for inclusion to enable the identification of current best evidence regarding the effectiveness of the use of bedrails in preventing falls among hospitalized older adults when compared with no use of physical restraints. 


\section{Search strategy}

The search strategy aims to find both published and unpublished studies. A three-step search strategy will be utilized in this review. An initial limited search of MEDLINE and CINAHL will be undertaken followed by an analysis of the text words contained in the title and abstract, and of the index terms used to describe the article. A second search using all identified keywords and index terms will then be undertaken across all included databases. Thirdly, the reference list of all identified reports and articles will be searched for additional studies. Studies published in Portuguese, English and Spanish will be considered for inclusion in this review. Studies published between 1980 and 2014 will be considered for inclusion in this review.

The databases to be searched include:

CINAHL

PsycINFO

Web of Science ${ }^{\mathrm{TM}}$ Core Collection

Cochrane Central Register of Controlled Trials

MEDLINE

Scielo

MedicLatina,

Academic Search Complete

Nursing \& Allied Health Collection: Comprehensive

The search for unpublished studies will include:

RCAAP - Repositório Cientifico de Acesso Aberto de Portugal

Banco de teses da CAPES (www.capes.gov.br)

ProQuest - Nursing and Allied Health Source Dissertations

"Grey Literature Report" from New York Academy of Medicine

Initial keywords to be used will be:

Bedrails

Hospital

Hospitalized

Aged

Elderly

Falls 
Side rails

Cot sides

Safety rail

During the process of conducting the search, various terminology and spelling of keywords will be taken into consideration as they might affect the identification of relevant studies.

\section{Assessment of methodological quality}

Papers selected for retrieval will be assessed by two independent reviewers for methodological validity prior to inclusion in the review using standardized critical appraisal instruments from the Joanna Briggs Institute Meta-Analysis of Statistics Assessment and Review Instrument (JBI-MAStARI) (Appendix I). Any disagreements that arise between the reviewers will be resolved through discussion, or with a third reviewer.

\section{Data extraction}

Quantitative data will be extracted from papers included in the review independently by two reviewers using the standardized data extraction tool from JBI-MAStARI (Appendix II). The data extracted will include specific details about the interventions, populations, study methods and outcomes of significance to the review question and specific objectives. For missing information or data that needs clarification, the authors of primary studies will be contacted. Any disagreements that arise between the reviewers will be resolved through discussion, or with a third reviewer.

\section{Data synthesis}

Quantitative papers will, where possible, be pooled in statistical meta-analysis using JBI-MAStARI. All results will be subject to double data entry. Effect sizes expressed as odds ratio (for categorical data) and weighted mean differences (for continuous data) and their $95 \%$ confidence intervals will be calculated for analysis. Heterogeneity will be assessed statistically using the standard Chi-square and also explored using subgroup analyses based on the different study designs, comparator or patient clinical condition. Where statistical pooling is not possible the findings will be presented in narrative form including tables and figures to aid in data presentation where appropriate.

\section{Conflicts of interest}

The authors declare that there are no conflicts of interest. 


\section{References}

1. Centers for Disease Control and Prevention, National Center for Injury Prevention and Control [Internet]. 2013 [cited 2014 Aug 15]. Available from: Web-based Injury Statistics Query and Reporting System (WISQARS).

2. American Geriatrics Society, British Geriatrics Society, American association of Orthopaedic Surgeons Panel on Falls Prevention. Guideline for the prevention of falls in older persons. Journal of the American Geriatrics Society. 2001; 49: 664-672.

3. Kannus P, Sievanen H, Palvanen M, Jarvinen T, Parkkari J. Prevention of falls and consequent injuries in elderly people. Lancet. 2005; 366:1885-93.

4. Vellas BJ, Wayne SJ, Romero LJ, Baumgartner RN, Garry PJ. Fear of falling and restriction of mobility in elderly fallers. Age Ageing. 1997; 26:189-193.

5. Bates D, Pruess K, Souney P, Platt R. Serious falls in hospitalised patients. Correlates and resource utilisation. Am J Med. 1995; 99:137-43.

6. Alexander BH, Rivara FP, Wolf ME. The cost and frequency of hospitalization for fall-related injuries in older adults. Am J Public Health. 1992; 82:1020-1030.

7. NPSA. Using bedrails safely and effectively [Internet]. 2007 [cited 2014 Sep 15]. Available from: http://www.nrls.npsa.nhs.uk/resources/?Entryld45=59815.

8. Mahoney J. Immobility and falls in the acute care setting. Clin Ger Medicine. 1998; 14: 699-72.

9. Vlahov D, Myers AH, al-Ibrahim MS. Epidemiology of falls among patients in a rehabilitation hospital. Arch Phys Med Rehabil. 1990; 71:8-12.

10. Halfon P, Eggli Y, Van Melle G, Vagnair A. Risk of falls for hospitalized patients: A predictive model based on routinely available data. J Clin Epidemiol. 2001; 54:1258-1266.

11. Schwendimann R. Frequency and circumstances of falls in acute care hospitals: A pilot study. Pflege. 1998; 11:335-341.

12. NPSA. Slips, trips and falls in hospital [Internet]. 2007 [cited 2014 Sep 15]. Available from: http://www.nrls.npsa.nhs.uk/resources/?Entryld45=59815.

13. Tang WS, Chow YL, Koh SSL. The Effectiveness of Physical restraints in Reducing Falls Among Adults in Acute Care Hospitals and Nursing Homes: A Systematic Review. Joanna Briggs Institute [Internet]. 2012 [cited 2014 Sep 15]; 10(5). Available from: http://www.joannabriggslibrary.org/index.php/jbisrir/article/view/4.

14. Australian Commission on Safety and Quality in Healthcare. Preventing falls and harm from falls in older people. Best Practice Guidelines for Australian Residential Aged Care Facilities [internet]. 2009 [cited 2014 Sep 15]. Available from: http://www.safetyandquality.gov.au/wp-content/uploads/2012/01/Guidelines-RACF.pdf.

15. Shanahan DJ. Bedrails and vulnerable older adults: how should nurses make 'safe and sound' decisions surrounding their use? Int Journ of Old Peop Nurs. 2012; 7(4): 272-81.

16. Medicines and Healthcare Products Regulatory Agency. Safe use of bedrails [internet]. 2013 [cited 2014 Sep 13]. Available from:

http://www.mhra.gov.uk/home/groups/dts-bs/documents/publication/con2025397.pdf.

17. Milner R, Smell A, Arora A, Sims D, Wales E. The prevalence of bedrail use in British hospitals. Age Ageing. 2003; 32: 555-6.

18. Raw J Stacey S. Are the days of bedrails coming to an end? Age Ageing. 2004; 33: 641-642. 
19. Flatharta T, Haugh J, Robinson SM, O'Keeffe ST. Prevalence and predictors of bedrail use in an acute hospital. Age Ageing. 2014; 43(6): 801-05.

20. $\mathrm{Ng} \mathrm{K}$, McMaster F, Heng B. The effectiveness of bedrails in preventing falls. Singapore Nurs J. 2008; 35(4): 10-17.

21. Gallinagh R, Slevin E, McCormack B. Side rails as physical restraints: the need for appropriate assessment. Nurs Older People. 2000; 13(7): 20-25.

22. Healey F, Oliver D, Milne A, Connelly JB. The effect of bedrails on falls and injury: a systematic review of clinical studies. Age Ageing. 2008; 37(4): 368-78.

23. Milner R, Smell A, Arora A, Sims D, Wales E. The prevalence of bedrail use in British hospitals. Age Ageing. 2003; 32: 555-6.

24. Raw J Stacey S. Are the days of bedrails coming to an end? Age Ageing. 2004; 33: 641-642.

25. Flatharta T, Haugh J, Robinson SM, O'Keeffe ST. Prevalence and predictors of bedrail use in an acute hospital. Age Ageing. 2014; 10.

26. Hoffman S, Powell-Cope G, Rathvon L, Bero K. BedSAFE: Evaluating a program of bed safety alternatives for frail elders. J Gerontol Nurs. 2003; 29(11): 34-42.

27. Parker K, Miles S. Deaths caused by bedrails. J Am Geriatr Soc. 1997; 45(7):797-802.

28. Liddle J, Gilleard C. The emotional consequences of falls for patients and their families. Age Ageing. 1994; 22(Suppl 4):17.

29. Anderson O, Boshier PR, Hanna GB. Interventions designed to prevent healthcare bed-related injuries in patients. Cochrane Database Syst Rev. 2012; 1:CD008931.

30. Capezuti E, Evans L, Strumpf N, Maislin G. Physical restraint use and falls in nursing home residents. J Am Geriatr Soc. 1996; 44(6): 627-633.

31. Van Leeuwen M, Bennett L, West $S$. Patients falls from bed and the role of bedrails in the acute care setting. Aust J Adv Nurs. 2001; 19(2): 8-13. 


\section{Appendix I: Appraisal instruments}

MAStARI appraisal instrument

\section{JBI Critical Appraisal Checklist for Randomised Control / Pseudo-randomised Trial}

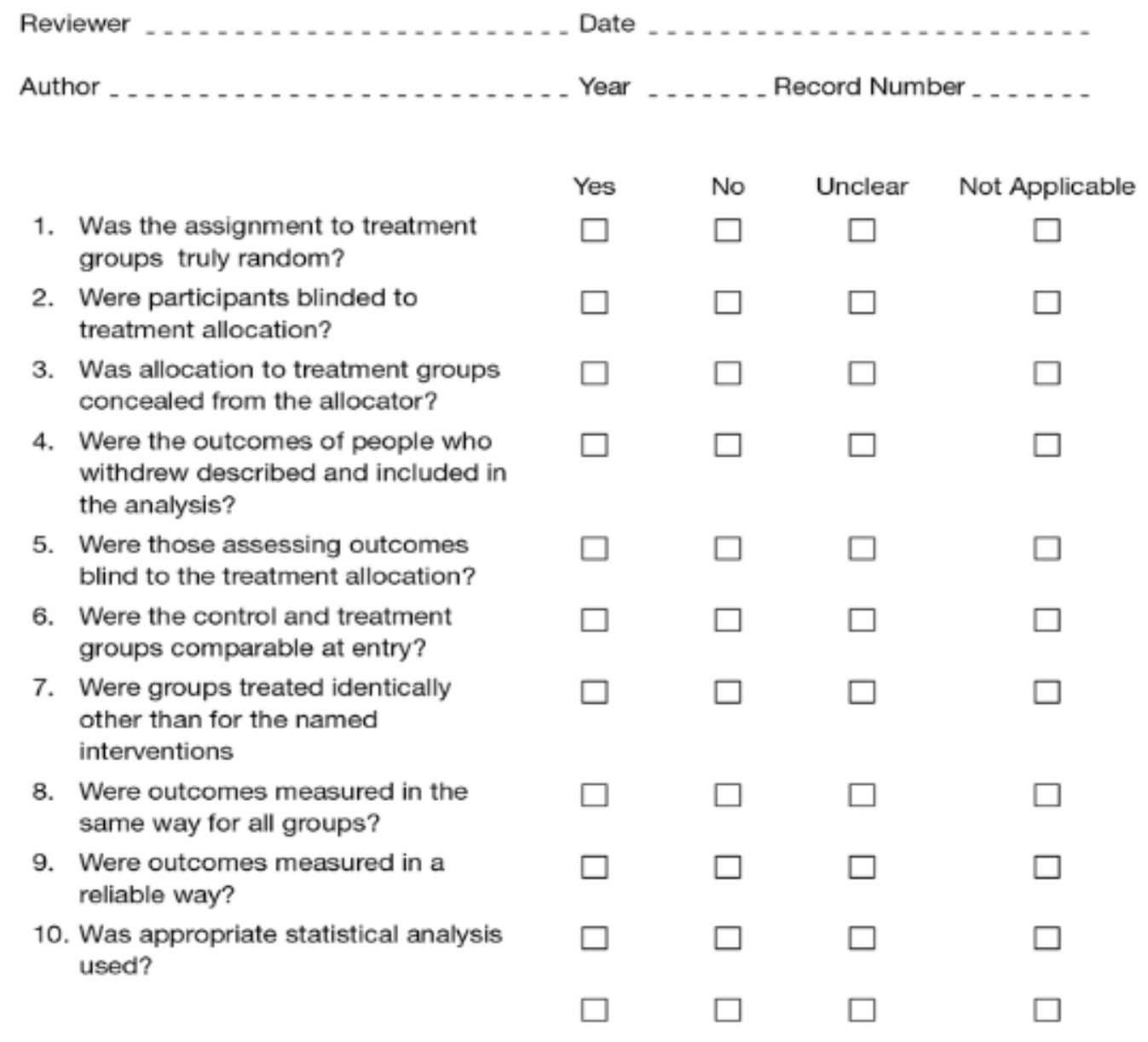

Overall appraisal: $\quad$ Include $\square \quad$ Exclude $\square \quad$ Seek further info.

Comments (Including reason for exclusion) 


\section{JBI Critical Appraisal Checklist for Descriptive / Case Series}

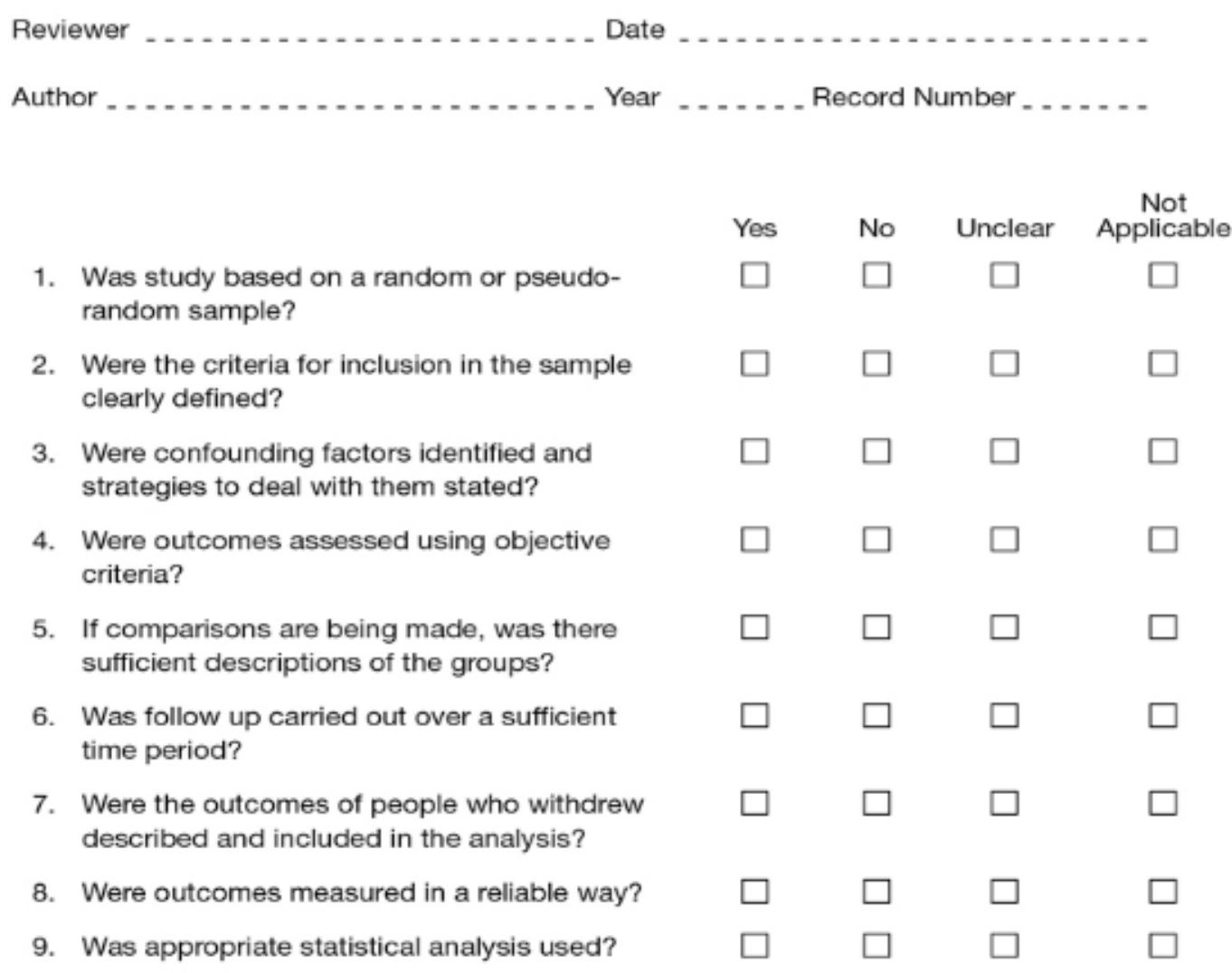

Overall appraisal: $\quad$ Include $\square \quad$ Exclude $\square \quad$ Seek further info

Comments (Including reason for exclusion) 


\section{JBI Critical Appraisal Checklist for Comparable Cohort/ Case Control}

\begin{tabular}{|c|c|c|c|c|}
\hline \multicolumn{5}{|l|}{ Reviewer } \\
\hline \multicolumn{5}{|c|}{ Author $\ldots \ldots$ Year } \\
\hline & Yes & No & Unclear & Not Applicable \\
\hline $\begin{array}{l}\text { 1. Is sample representative of patients } \\
\text { in the population as a whole? }\end{array}$ & $\square$ & $\square$ & $\square$ & $\square$ \\
\hline $\begin{array}{l}\text { 2. Are the patients at a similar point in } \\
\text { the course of their condition/illness? }\end{array}$ & $\square$ & $\square$ & $\square$ & $\square$ \\
\hline $\begin{array}{l}\text { 3. Has bias been minimised in relation } \\
\text { to selection of cases and of } \\
\text { controls? }\end{array}$ & $\square$ & $\square$ & $\square$ & $\square$ \\
\hline $\begin{array}{l}\text { 4. Are confounding factors identified } \\
\text { and strategies to deal with them } \\
\text { stated? }\end{array}$ & $\square$ & $\square$ & $\square$ & $\square$ \\
\hline $\begin{array}{l}\text { 5. Are outcomes assessed using } \\
\text { objective criteria? }\end{array}$ & $\square$ & $\square$ & $\square$ & $\square$ \\
\hline $\begin{array}{l}\text { 6. Was follow up carried out over a } \\
\text { sufficient time period? }\end{array}$ & $\square$ & $\square$ & $\square$ & $\square$ \\
\hline $\begin{array}{l}\text { 7. Were the outcomes of people who } \\
\text { withdrew described and included in } \\
\text { the analysis? }\end{array}$ & $\square$ & $\square$ & $\square$ & $\square$ \\
\hline $\begin{array}{l}\text { 8. Were outcomes measured in a } \\
\text { reliable way? }\end{array}$ & $\square$ & $\square$ & $\square$ & $\square$ \\
\hline $\begin{array}{l}\text { 9. Was appropriate statistical analysis } \\
\text { used? }\end{array}$ & $\square$ & $\square$ & $\square$ & $\square$ \\
\hline Overall appraisal: & Exclude & $\square$ & $\mathrm{Se}$ & s further info. $\square$ \\
\hline
\end{tabular}




\section{Appendix II: Data extraction instruments}

MAStARI data extraction instrument

\section{JBI Data Extraction Form for Experimental / Observational Studies}

\begin{tabular}{|c|c|c|c|c|c|}
\hline \multicolumn{6}{|l|}{ Reviewer ... } \\
\hline \multicolumn{6}{|c|}{ Author $\ldots \ldots$} \\
\hline \multicolumn{6}{|c|}{ Record Number } \\
\hline \multicolumn{6}{|c|}{ Study Method } \\
\hline RCT & $\square$ & Quasi-RCT & $\square$ & Longitudinal & $\square$ \\
\hline Retrospective & $\square$ & Observational & $\square$ & Other & $\square$ \\
\hline \multicolumn{6}{|l|}{ Participants } \\
\hline Setting & & & & & \\
\hline
\end{tabular}

\section{Sample size}

Group A Group B

\section{Interventions}

Intervention A

Intervention B

Authors Conclusions:

Reviewers Conclusions: 


\section{Study results}

\section{Dichotomous data}

\begin{tabular}{|l|l|l|}
\hline Outcome & $\begin{array}{c}\text { Intervention ( ) } \\
\text { number/total number }\end{array}$ & $\begin{array}{c}\text { Intervention ( ) } \\
\text { number/total number }\end{array}$ \\
\hline & & \\
\hline & & \\
\hline & & \\
\hline & & \\
\hline
\end{tabular}

\section{Continuous data}

\begin{tabular}{|l|l|l|}
\hline Outcome & $\begin{array}{c}\text { Intervention ( ) } \\
\text { number/total number }\end{array}$ & $\begin{array}{c}\text { Intervention ( ) } \\
\text { number/ total number }\end{array}$ \\
\hline & & \\
\hline & & \\
\hline & & \\
\hline & & \\
\hline
\end{tabular}

